\title{
Evaluation of the collaboration process from an individual and collaborative perspective
}

\author{
Mayela Coto \\ Universidad Nacional \\ Heredia, Costa Rica \\ mcoto@una.cr
}

\author{
Sonia Mora \\ Universidad Nacional \\ Heredia, Costa Rica \\ sonia.mora.rivera@una.cr
}

\author{
Cesar Collazos \\ Universidad del Cauca \\ Colombia \\ ccollazo@unicauca.edu.co
}

\begin{abstract}
Many proposals to evaluate the collaborative process focus on "measure" the group's participation in the fulfillment of the activity and do not consider the individual aspect. This paper reports the results of an exploratory study which aims to analyze the potential of the Google Drive (GD) tool for assessment of collaborative work process from an individual and collaborative perspective.
\end{abstract}

\section{Categories and Subject Descriptors}

H. Information Systems

H.5 Information Interfaces and Presentation

H.5.3 Group and Organization Interfaces - Computer-supported cooperative work

\section{General Terms}

Design, Human Factors

\section{Keywords}

Collaborative learning, CSCL, group evaluation, individual evaluation, Google Drive

\section{INTRODUCTION}

It has been widely documented that, properly used, technology can be a tool that positively impacts the teaching and learning processes [1][2]. It can become an ally for faculty in the processes of design, planning, development, implementation and evaluation of an educational process, in addition to facilitating the interaction between them and students.

Additionally, the technology has the potential to contribute to the development of learning environments promoting the overall development of students and their multiple capabilities [3]. It can motivate individual work, and encourage interaction with other students. In this manner, technology can add a new dimension to collaborative learning perspective, understood as one in which students work with peers to achieve common learning goals [4].

\footnotetext{
Permission to make digital or hard copies of all or part of this work for personal or classroom use is granted without fee provided that copies are not made or distributed for profit or commercial advantage and that copies bear this notice and the full citation on the first page. To copy otherwise, or republish, to post on servers or to redistribute to lists, requires prior specific permission and/or a fee.

Interaccion'14, Sep 10-12, 2014, Puerto de la Cruz, Tenerife, Spain. Copyright 2014 ACM 978-1-4503-2880-7/12/10 ..\$15.00.

DOI: http://dx.doi.org/10.1145/2662253.2662342
}

Collaborative learning aims to encourage students to build knowledge through exploration, discussion, and negotiation [5]; however it is important to understand that putting a group of students around a common task does not guarantee a true collaboration, to accomplish this it is necessary to structure activities that promote such collaboration [6], [7].

One of the most complex aspects of collaborative learning is aspect related with evaluation. Although there are several mechanisms and proposals to assess the collaboration process there is still no fully accepted model due to the variety of aspects to analyze. Many proposals focus on trying to "measure" the group's participation in the conduct of the activity and do not consider the individual aspect. According to [8], when teachers evaluate a whole group equally a disincentive to work occurs among students because some of them tend to work less and take advantage of the efforts of others, aspect called as free-riding. This in turn causes some faculty to look at collaborative work skeptically by not allowing them to properly identify individual effort.

One of the essential components in collaborative learning is individual responsibility associated with the group work. Each member is responsible for accomplish their task without taking advantage of the other group members' efforts. The group should be able to assess both the progress made in achieving the objectives and the efforts of each group member. This individual contribution in group work is an important element that generates extensive discussions among faculty that, while promoting collaborative learning in their class, face the challenge of evaluating the learning of content and the development of implicit skills in collaborative experiences. However, according to [7], the individual contribution in this type of pedagogical approach has been scarcely studied.

In this manner, this paper reports the results of an exploratory study which aims to analyze the potential of the Google Drive tool (GD) for assessment of collaborative work process, comprehensively considering both group work and individual contributions. The remainder of this paper will proceed as follows. Section II will review the theoretical framework, while section III will provide an overview of the study methodology and the design of the activity. Section IV presents the results, and the paper closes with concluding remarks in section $\mathrm{V}$. 


\section{THEORETICAL BACKGROUND 2.1 Collaborative Learning}

According to [9], in today's society a social and interdependent perspective of each of the members of a society is being imposed, in which the unavoidable need for collaboration with others is required, and where every time there's less room to accommodate persons acting as isolated and independent beings.

The term collaborative learning refers to a teaching-learning strategy in which students have to work with others to meet a learning objective and achieve a certain task. This implies the need for mutual commitment between students and establishes a coordinated effort to respond to the assigned task [10]. Thus, this way of learning is far from competitive or individualistic methodologies that do not require interaction with other students [11].

In [3], the author indicates that collaborative learning facilitates the disappearance of students as passive observers and repetitive receptors, creating spaces for confrontation of multiple perspectives and negotiation in a learning process that leads to the integral development of the participants. In collaborative learning each of the group members must be committed to the goal of the group, and be aware that their contribution to the group is not competitive but part of a positive interdependence where achieving the joint goal is more important than individual contributions [12].

In this way collaborative learning creates spaces with multiple possibilities and opportunities for exchange, encouraging the development of individual and group skills from the negotiation between the students, promotes the growth of the group and a better knowledge transfer than individual learning [13] [14].

In [15] the following characteristics of collaborative learning are highlighted: (1) positive interdependence: to pursue a common goal, group members are motivated to help each other; (2) encouraging interaction: members of a group must interact with each other to solve the problem efficiently through individual contributions; (3) individual responsibility: each member of the group takes its responsibility to contribute to the learning of all; (4) development of skills: working together students develop academic skills and interpersonal skills such as teamwork, leadership, and negotiation; (5) assessment of group members: maintain a good working relationship with others and be willing to give and receive feedback and constructive criticism on individual and group contribution. All the above characteristics make collaborative learning a form of desirable learning.

According to [16], the two main characteristics of collaborative learning are positive interdependence and individual responsibility. Additionally, according to [17], the key to understand collaborative learning is to recognize the relationships established between the learning situation, the interactions that emerge among students and therefore the processes and effects that are generated.

Collaborative learning is not a simple mechanism, because if you talk about "learning from collaboration" you must also speak of "learning by being alone". Cognitive systems of individuals do not learn because they are individual, but because they perform activities (reading, predicting, etc.) that involve some learning mechanisms (induction, prediction, compilation, etc). Similarly, the pairs do not learn because they are two, but because they perform some activities involving specific learning mechanisms. This includes the activities and / or mechanisms implemented individually, but also the interaction between partners generates additional activities (explanation, mutual regulations, etc.). The area of collaborative learning refers precisely to these activities and mechanisms. These may occur more frequently in a collaborative learning than in and individual context. However, there is no certainty that these mechanisms occur in any collaborative interaction. Moreover, they do not occur only during the collaboration. At a certain level of description - at least to a neuronal level - the mechanisms potentially involved in a collaborative learning are the same as those involved in individual cognition [17] [18].

In [7], the authors define the collaborative learning process as a set of activities to be performed by the facilitator and the students. Those activities must be properly designed to ensure that the process is really effective. According to the type of tasks to be performed, the authors divide the process into three stages, where the first two are mainly associated with the facilitator and the last one with students: (1) pre-process: step in which the tasks for organization and strategy definition are set; (2) in-process: a step in which the interactions of the learning process take place, such as: positive interdependence, intra-group cooperation, control and monitoring of the success criteria, the mutual support, and the delivery of the final product; (3) post-process: step in which the assessment tasks are held.

\subsection{CSCL}

The CSCL (Computer-Supported Collaborative Learning) is an educational paradigm that focuses on the use of information and communication technologies (ICTs) as tools to enhance collaborative learning [19]. Generally, distributed CSCL environments involve students working in groups together on a common project or problem [20]. In this approach the collaborative learning elements are present, but the dynamic varies due to the use of technology to mediate learning. This mediation in addition to leading to changes in the organization of learning, also reported gains in student learning, such as critical thinking skills, independent learning and personal and social skills group [1] [2].

According to [21], collaborative learning mediated by the computer involves two important ideas. The first is the idea of learning in groups, interacting with others, taking as premise that sharing goals and distributing responsibilities are desirable forms of learning. Second, it emphasizes the computer as the mediating element that supports this process, favoring the processes of interaction and the joint solution of problems or assignments.

Collaboration can be seen as a special form of interaction. CSCL analyzes how technology and collaboration facilitates the sharing of knowledge and experience in work groups [22]. With ICT support, students can form their ideas, focus on the task and deepen together in the solution without having to be together physically.

Collaborative learning supported by ICTs, has the following benefits [3]: (1) encourages interpersonal communication to facilitate the exchange of information and dialogue and discussion among students; (2) facilitates collaborative work by allowing students to share information, work with documents and facilitate joint problem solving and decision making; (3) allows tracking the progress of the group, individually and collectively; (4) 
provides access to information and learning content; and (5) facilitates the management and administration of students.

However, despite its potential benefits, it is not easy to plan this kind of learning environments. As mentioned above, it is not enough to put a group of students to interact in order for learning to occur. Different elements must be articulated to achieve the joint processes of exchange and knowledge construction. Additionally, the design of the collaborative activities should promote that the success of an individual is linked to the success of the others [21] [7].

One way to promote positive interdependence, interaction and group process is by assigning roles to students. Groups also tend to function more effectively when members have designated roles. These roles can be determined by the facilitator or established by the groups themselves from a list, this will depend on criteria such as educational maturity of the students, their familiarity with group work and the time available for the activity [16].

\subsection{Evaluation}

The evaluation process is a critical step in any educational process. According to [23] the evaluation is a key element because the information it provides to teachers and its implications for teachers, students, the educational system and society.

Many studies have emphasized the importance of the active participation and collaboration among students in order to solve a task properly. However, in most teaching-learning scenarios, evaluation of collaborative learning is done by measuring the quality of the end product or by examination or testing students to determine how much they have learned, i.e. a quantitative evaluation of the quality of the results of the collaborative process is obtained, leaving aside individual work [24]. This is because it is not easy to accurately determine the percentage of individual and group work [25].

Collaborative learning activities generally have among its objectives, the achievement of a collaborative product, the effective functioning of the work group and individual learning. According to [26], the best option you have to evaluate the collaborative process that takes place in a group of students is using information obtained through monitoring activity during development. This information must be quantifiable and easy to interpret. In this sense, one of the most important aspects in the evaluation of the collaborative process is the definition of a set of criteria used to qualify collaboration through the process.

In [24] and [7], the authors propose a collaboration index based on a simple average of five indicators of success in a collaborative learning process, based on the tasks outlined by [11]. The five indicators proposed by [24] are the use of strategies, intra-group cooperation, reviewing success criteria, monitoring and the ability to provide support. Then they establish a Cooperation Index (CI) as the average of these five indicators. In [7] [26], the "provide support" indicator is changed for the "performance" indicator, which is based on the outcome of the activity to measure overall performance of the group. Some of these indicators are strongly supported by the semantic analysis of the messages exchanged by the students in the collaborative process.

\subsection{Technological Tools}

The new forms of access to information, communication and new technology capabilities require university staff to adapt their methodologies and educational tools to the profiles of the new students. Currently there are numerous tools that facilitate the connection of students with thematic content through databases, specialized programs on the Internet, classifying documents programs, word processing programs to represent information, programs to develop the information obtained and programs to communicate and share information [27]. Additionally, there are numerous technological tools to promote collaborative learning among students, but these are not always introduced in teaching in a systematic way [28].

In the list of the top 100 learning tools-Top 100 Tools for Learning (http://c4lpt.co.uk/top100tools/) - the Centre for Learning \& Performance Technologies, the Google Drive tool appears in the second position only overtaken by Twitter. This list shows every year a review of international education experts on the best tools for teaching and learning.

Google Drive is a service for free online storing of files up to five gigabytes. Its main functionality is to allow several authors work collaboratively, synchronous or asynchronous, on various types of documents online - text, spreadsheets, presentations and forms[29]. Each user has its own storage space, through which they can share documents with other users and access documents shared by other contributors. Users can have the owner role, the role of reviewers (can edit the documents and invite other users) or readers (can only read documents). Documents may have several partners but only one owner.

GD is a free and easy tool to use, only a web browser is needed, and it is not needed to install any external program to store and manage documents. Some of the features of this online service are: (1) edit documents online, synchronously or asynchronously, with the people invited as partners; (2) maintain, for simultaneous editing, a conversation "chat" with the reviewers; (3) it provides a historical revision of documents, with the ability to roll back to any version. The revision history allows users to see the changes made for each editor to a document and the date and time of the changes. GD is also a familiar tool for teachers and students. In this sense, GD represents many advantages to support the CSCL environments.

\section{DESIGN OF THE ACTIVITY}

Starting from the premise that educational activities are one of the best means of learning that students have, an exploratory collaborative activity took place in the EIF200 Introduction to Programming course during the 1st semester of the 2014 academic year. This course is the first career course of the Information Systems Engineering study program of the Universidad Nacional of Costa Rica.

With the knowledge that collaborative tools per se do not automatically produce collaborative processes [30], it was planned an activity that allowed, in the designated time, to achieve a common goal and encourage positive interdependence from each group member. The level of knowledge of students on the subject and the level of difficulty of the activity was also taken into account. 
The activity was planned to take place in the computer lab with 5 groups of about 15 to 18 students each. The task was scheduled as follows: 2 groups from 7 to 9 am, 2 groups from 9 to 11 am, and 1 group from 11 to $1 \mathrm{pm}$. However, because of Internet overload on campus, the access to Internet on that day in particular was very unstable from 9am, so most groups faced serious problems with the activity. Because of this situation, the analysis was performed only for the 9 groups at 7 a.m. with a total of 36 students. The activity was designed to be carried out in the two hours established for class. Being this a limited amount of time, the choice of an easy tool to use was a very important point. It should not require too much explanation, and should facilitate the organization and negotiation process between the members of the groups previously established by each teacher. Considering that all students have an institutional Google email account, that the GD tool is easy to use and familiar to students, and it has a chat that allows the internal organization of the group, it was decided to select GD for the activity.

The objectives set by professors to achieve with the educational activity were the following: (1) that students learn and understood the main concepts associated with the organization of a computer (central processing unit, control unit, memory, processor, I / O devices, etc.); (2) that students could perform an collaborative activity using digital tools; (3) that students could properly appropriate some specific roles; (4) that students know a tool that facilitates collaborative work, more specifically GD.

Before the activity, each teacher conducted a previous work by creating the groups, a GD space for each group, and uploading a document that established the basis for the realization of the activity and the requirements necessary to achieve a good performance in it. Also an invitation was send by email to each student according to the corresponding group. In Figure 1 the description of the activity given to students is shown.

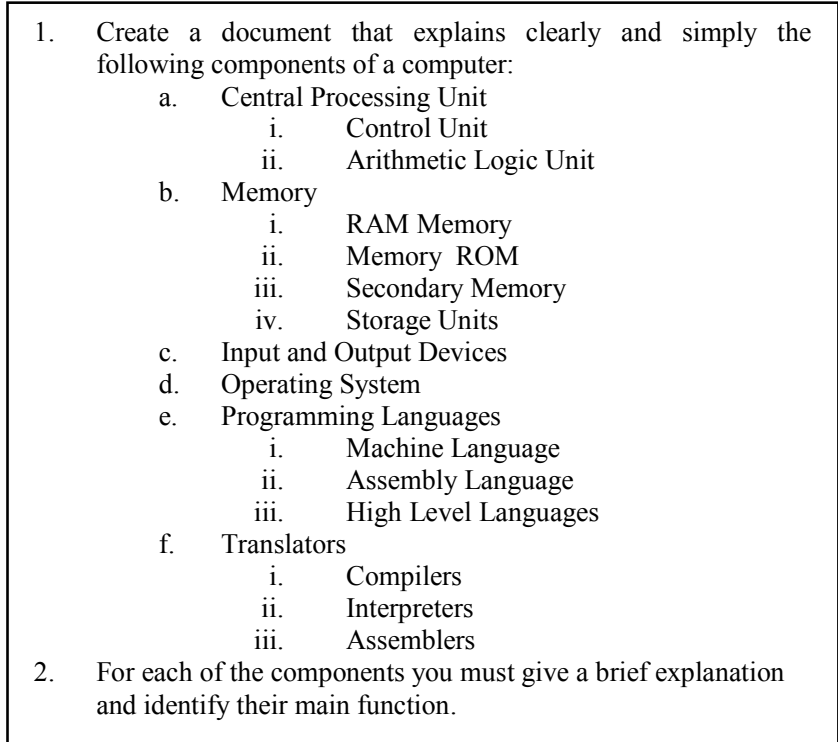

\section{Figure 1. Activity's description}

Following the guidelines of [7], the activity was designed to be completed in three phases, shown in Figure 2.
As it can be seen the first phase of the activity was to briefly explain the formation of the groups, the operation of the GD tool, the use of the chat, as well as the activity itself. In the second phase, following the concept of positive interdependence, the students were told that they should adopt different roles (text search, image search, integrator and editor) to achieve the ultimate goal, they were provided with a short definition of each role and were suggested to consider the "talents" of each participant at the time of distribution [16]. With regard to the roles and their distribution, the intention was, given the limited amount of time, to prevent students opting for the "normal" division of labor (according to topics), and to ensure that all members of the group, in one way or another had contact with all the thematic concepts as they are part of the course syllabus.

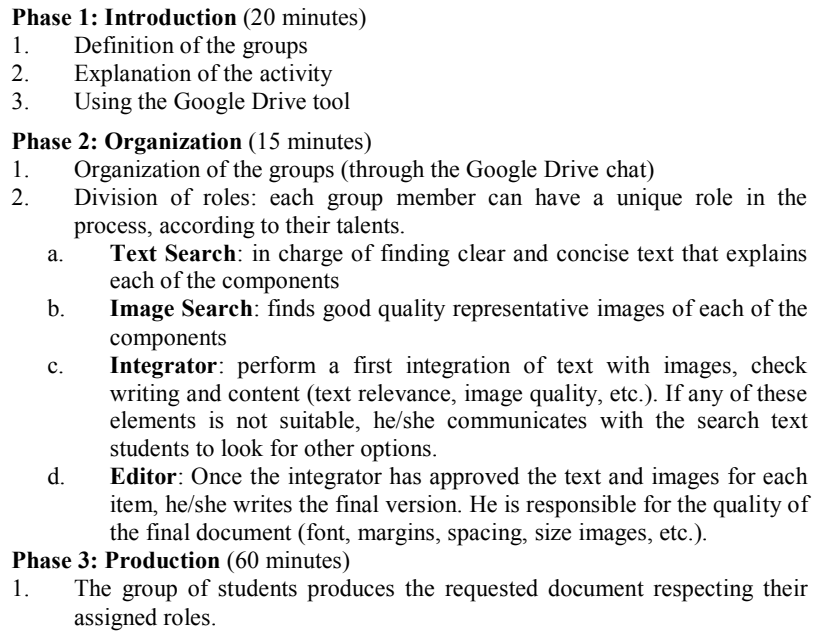

d. Editor: Once the integrator has approved the text and images for each item, he/she writes the final version. He is responsible for the quality of the final document (font, margins, spacing, size images, etc.)

Phase 3: Production (60 minutes)

1. The group of students produces the requested document respecting their assigned roles.

Figure 2. Phases and roles

Finally in the third phase, students have to complete the activity in 60 minutes. Although all students were physically in the same room, a synchronous interaction was promoted, that is, all communication was mediated by the computer and the students had to use the chat as a means of organization.

The assessment, in any context, is a constant concern for students and teachers. In a collaborative work environment, assessing each student fairly and equitably, according to their effort, is of interest to both students and teachers. Under this scenario it was decided to evaluate the activity from two components: group work and individual contribution, defining the evaluation criteria of the activity as it follows: (1) the extent to which the group keeps the strategy to achieve the objective; (2) the level of completeness of the activity according to the requirements set forth previously; (3) and the individual contribution of each member to the final product.

\section{RESULTS}

For the evaluation of the collaborative activity, it was proposed to consider: the final product (FP) from the information provided by GD; and individual contribution (IC) considering the historical revision provided by GD. This option leaves evidence of the students interventions (any changes made to the document), and also allows to recover older versions of the document, being able in this way to identify what changes were made at a given time 
and who were involved in that changes. In order to make an assessment of the activity that does not involve a lot of effort for the teacher or facilitator, the registrations made by GD during the preparation of the document were considered as the individual contribution of each student.

Unfortunately, the GD chat works in a very unique and different way from other Google chats (Gmail chat for example), since it is only available while you are working online in the document, this implies that the chat information is not saved and cannot be recovered once the document is closed. This entails an important limitation of the tool and makes it impossible to apply the Cooperation Index (CI) defined above and analyze the type of messages exchanged among students regarding work organization and conduct of the activity, as done by [ 8] [24] [26].

According to the above, then the information provided by GD to evaluate the collaborative activity consists, firstly, of two elements: (1) the final group product and (2) the individual contribution. From the final document it can be assessed whether the groups reached or not the objectives proposed by the activity, and, for the purposes of this experiment, we consider the individual contribution as the number of changes recorded by GD for each student in the final product's development, as mentioned above. In the next section we make an analysis of each of these elements and how they were considered to assess the activity.

\subsection{Evaluation of the Final Product (FP)}

The final product is evaluated in terms of the results obtained in each of the requirements of the activity (fig. 1). The evaluation of the final product was performed in two parts; first the degree of completeness of the theoretical concepts and illustrative images was evaluated, obtaining a percentage value to each item. Subsequently, a simple average of these percentages is calculated to obtain the final score. For example, the group G2 (see Table 1), reached $100 \%$ in the completeness of the text but only $50 \%$ in terms of images, so that the average of fullness is $75 \%$.

It can be seen that the overall success rate (if this is considered as having done everything requested by the activity) is low. The average completeness of the task is $64 \%$. Some reasons for this performance can be associated with problems with Internet during the activity, and with little experience from students with the type of activity. Some groups were also affected by the strategy followed to address the work, as will be discussed later.

Table 1. Level of completeness of the activity

\begin{tabular}{|c|c|}
\hline Group $\mathbf{N}^{\circ}$ & $\begin{array}{c}\text { \% completeness of } \\
\text { FP }\end{array}$ \\
\hline G1 & 70 \\
\hline G2 & 75 \\
\hline G3 & 40 \\
\hline G4 & 95 \\
\hline G5 & 95 \\
\hline G6 & 95 \\
\hline G7 & 35 \\
\hline G8 & 25 \\
\hline G9 & 45 \\
\hline
\end{tabular}

Source: documents obtained through GD

\subsection{Evaluation of the individual contribution (IC)}

The individual contribution of each group member was evaluated according to the information provided by GD on the number of times each contributor made changes to the document. Thus the amount of interventions required to complete the document presented by each group were initially calculated, then the average amount of interventions made by the group is determined, with this information for each student an intervention ratio was determined according to this average (AI) in order to weigh each student's contribution to the final product (AIP). For example, in Table 2 the data belonging to the group G5 is shown. From the data we can see that GD registered for the student E2, a total of 110 interventions, and since the mean of that group's interventions was 77, the student E2 contribution corresponds to $153 \%$ on the final product.

Table 2: Individual contribution Group G5

\begin{tabular}{|c|c|c|}
\hline Student & \# Inter. & IC \\
\hline E1 & 49 & 68 \\
\hline E2 & 110 & 153 \\
\hline E3 & 103 & 143 \\
\hline E4 & 26 & 36 \\
\hline Mean & 77 & \\
\hline
\end{tabular}

Source: historical revision data

From these data, a facilitator could calculate in a relatively simple way, a grade for the activity that evaluates to some extent the individual contribution. For example, if it is decided that the final product (FP) has a weight of $70 \%$ and the individual contribution a weight of $30 \%$, the final grade for students in the group G5 as shown below:

Table 3. Final grade Group G5

\begin{tabular}{|c|c|c|c|c|}
\hline Student & FP & IC & WIC & FG \\
\hline E1 & 95 & 68 & 65 & 86 \\
\hline E2 & 95 & 153 & 145 & 110 \\
\hline E3 & 95 & 143 & 136 & 107 \\
\hline E4 & 95 & 36 & 34 & 77 \\
\hline
\end{tabular}

Source: analysis from the authors

The column of weighted individual contribution (WIC) considers the contribution of each student with reference to the grade obtained in the final product, thus calculated as IC * FP. The final grade, weights the WIC at $30 \%$ and the FP at $70 \%$. As it is expected the final grade for each student will be distributed based on the 95 grade obtained but with a variation of +-30 points weighting the individual contribution. This way the effort of each student is reflected in their final grade.

\subsection{Understanding the collaborative process}

The above grades, despite giving an assessment of the activity considering both the group and individual effort, present some aspects that should be analyzed in a deeper way by the facilitator is needed in order to understand deeper the process. Some of them are:

1. The first one is related to the registration of individual contribution. For example, in the G7 and G9 groups, which are two of the groups with the lowest percentage of completion (see Table 1), students used a strategy of creating a separate image 
folder instead of integrating text and images in the document. This decision had implications for both the final product and the individual contribution. For the G7 group, if the final document is analyzed, it is observed that students only complete the text by $60 \%$ and the images by $10 \%$, however the student $\mathrm{E} 4$ with the role of "image search" creates a folder with 15 pictures, but only one of them is integrated into the final document. This clearly affects the grade of the final product, in this case calculated as a simple average of these two figures. The decision to work in this way also has implications for assessing the individual contribution according to information provided by GD, as in the case of student E4. For this student 0 interventions are reported in the final document, which clearly affects their final grade negatively despite the work done with the search and selection of images.

The case of the G9 is similar, in this group the student E3 with the role of image finder creates different folders with images but none of these are incorporated into the text. The G9 group achieved $90 \%$ completeness of the text but $0 \%$ in the case of images, so that its resulting performance from the point of view of the final product is $45 \%$. Similarly the student's grade E3 is affected because their individual contribution is not recorded in the final document.

2. Another drawback is that GD does not display information in a way that allows monitoring the strategy used by groups to solve together the problem. In addition, not counting with the chat log make not possible to understand how were the communication and organization among the group members.

To gain a better understanding of the collaborative process, it was decided to supplement the information in GD with an online questionnaire that provides individual information on the experience of each student, but when analyzed for groups gives an indication of the characteristics and behavior of them. Of 36 students who participated in the activity, 33 of them completed the questionnaire. The percentages shown in the following tables refer to the number of students who answered the questionnaire in each of the groups.

\subsection{Regarding Strategy}

The way the roles were assumed for the development of the activity is considered part of a strategy to address the task and achieve a final product. In the context of the proposed activity, it can be said that by have indicated the specific roles to be undertaken by students, a strategy to solve the problem was previously defined.

However, from the perspective of understanding how the strategy would allow them to achieve the final goal, it was decided to analyze the group' clarity in identify roles. It is assumed that a clear identification of roles at the beginning of the task will require less coordination efforts during implementation. Also, it was considered that keeping the specific roles throughout the execution of the task, is an indicator that shows whether each member of the group was able to understand how their contribution relates to the common goal of the group. In order to assess the clear identification of roles, the students were asked to indicate which role they had represented in the development of the activity. Given the fact that the roles were not duplicated in the group (except for the G8 group of 5 members), it is assumed that only when each student indicated a different role there was a clear distribution of them. For example, in the G5 group, two students reported having had the role of "integrator", indicating that as a group they were not really clear on the distribution of roles. The information whether it was or not a clear identification of roles (IR) in the groups is shown in Table 4.

To evaluate the appropriation of roles (AR) and maintenance of them during the course of the activity, students were asked in the questionnaire whether it was easy or not for them to keep the selected role. In this case in the G5 group, 3 of the 4 members affirmed have remained in their role, which would indicate that $75 \%$ of the group managed to grab their role properly. The results are shown in Table 4.

Table 4. Results regarding the identification and appropriation of roles

\begin{tabular}{|c|c|c|}
\hline Group N $^{\circ}$ & IR & \%AR \\
\hline G1 & NO & 67 \\
\hline G2 & NO & 75 \\
\hline G3 & YES & 100 \\
\hline G4 & NO & 67 \\
\hline G5 & NO & 75 \\
\hline G6 & YES & 100 \\
\hline G7 & NO & 75 \\
\hline G8 & NO & 60 \\
\hline G9 & NO & 50 \\
\hline
\end{tabular}

Source: Online questionnaire

It can be seen that the management of roles was a difficult aspect for groups since only 2 groups of 9 had a clear identification and distribution of roles. It is interesting to observe the relationship between this condition and the maintenance of roles throughout the process, as the only two groups where $100 \%$ of their members reported to have remained in their role were the G3 and G6, which are the same groups in which role distribution was clear. Students who reported not remaining in their role, indicated that there was never a clear division of them or that at times they took on another role in order to finish the activity on time.

Starting from the premise that a clear strategy, reflected in this case in a good understanding and management roles, is a fundamental component of the collaborative process, it is considered important to integrate this aspect in the final assessment of the activity. Table 5 shows how it would affect the final grade (FG1) for the G5 group considering that $75 \%$ of its members took and maintained their roles for the joint construction of the document (see \%AR in Table 4), In this manner, $\mathrm{FG} 1=\mathrm{WIC} * 0.3+(\mathrm{FP}+\mathrm{AR}) / 2 * 0.7$

Tabla 5. Final Grade Considering Strategy (FG1)

\begin{tabular}{|c|c|c|c|c|c|}
\hline Student & FP & IC & WIC & FG & FG1 \\
\hline E1 & 95 & 68 & 65 & 86 & 79 \\
\hline E2 & 95 & 153 & 145 & 110 & 103 \\
\hline E3 & 95 & 143 & 136 & 107 & 100 \\
\hline E4 & 95 & 36 & 34 & 77 & 70 \\
\hline
\end{tabular}

Source: GD and online questionnaire

Now the final grade (FG1) integrates both, group work and individual effort. The grade was calculated considering the information supplied by GD and the online questionnaire, and it does not imply too much work for teachers or facilitators. 


\subsection{Other aspects to consider}

There are other key aspects of the collaborative process in a group that should be analyzed, such as the facility to get organized, the learning achieved through the activity, and the use of the tool that supports the collaborative process. Below these aspects are analyzed from the students' perspective.

The facility to organize themselves as a group using virtual tools understood in the activity as the facility for synchronous distributed group work and the use of chat as a communication mean - is an important aspect of collaborative online work. The perception of students regarding these two aspects can be seen in Table 6.

\section{Table 6. Group perception about their organization}

\begin{tabular}{|c|c|c|}
\hline $\begin{array}{c}\text { Group } \\
\mathbf{N}^{\circ}\end{array}$ & $\begin{array}{c}\text { Was it easy to work } \\
\text { collaboratively } \\
\text { online? }\end{array}$ & $\begin{array}{c}\text { Was the chat a } \\
\text { useful mean of } \\
\text { communication? }\end{array}$ \\
\hline G1 & $67 \%$ & $100 \%$ \\
\hline G2 & $50 \%$ & $75 \%$ \\
\hline G3 & $50 \%$ & $100 \%$ \\
\hline G4 & $67 \%$ & $100 \%$ \\
\hline G5 & $50 \%$ & $100 \%$ \\
\hline G6 & $75 \%$ & $100 \%$ \\
\hline G7 & $50 \%$ & $100 \%$ \\
\hline G8 & $100 \%$ & $100 \%$ \\
\hline G9 & $75 \%$ & $100 \%$ \\
\hline
\end{tabular}

Source: Online questionnaire

It is easy to see that most of the students think that the chat was a useful tool when making group agreements. However, with the exception of the G8 group, at least one member of each group felt that the online work was not easy. In this regard most of them indicate it was not easy because the internet connection in the laboratory was very unstable and a student says that it was because Google Drive was a new tool for him. No student indicates that the work was difficult because of problems with the organization of the group.

Additionally we considered the perception of students towards the learning achieved. This last element, despite being an individual judgment of each student regarding their learning, is seen as the group's learning under the basic premise of collaborative learning that all members should have an interest and commitment towards their peers learning. Furthermore, the design of the activity and the established roles had the goal that all students could have, in one way or another, contact with all the content topics, thus in this way the learning is not fragmented in topics and a more comprehensive learning could be achieved. Thus, for example, it can be seen in Table 7, that G2 has a $100 \%$ indicating that the 4 members of the group expressed having learned with the activity, and the $33 \%$ of the group G1 indicates that of 3 students who answered the questionnaire in this group only 1 of them said to have learned. Although a high percentage of the total student population $(88.9 \%)$ report having learned about the thematic content developed in the activity, it is clear that promoting learning is not an easy task, so this must always be an important goal for facilitators when designing any learning situation.
Tabla 7. Perception of the achieved learning level

\begin{tabular}{|c|c|c|}
\hline $\begin{array}{c}\text { Group } \\
\mathbf{N}^{\circ}\end{array}$ & $\begin{array}{c}\text { \% completeness } \\
\text { of FP }\end{array}$ & $\begin{array}{c}\text { Positive perception } \\
\text { towards learning }\end{array}$ \\
\hline G1 & 70 & $33 \%$ \\
\hline G2 & 75 & $100 \%$ \\
\hline G3 & 40 & $100 \%$ \\
\hline G4 & 95 & $100 \%$ \\
\hline G5 & 95 & $75 \%$ \\
\hline G6 & 95 & $100 \%$ \\
\hline G7 & 35 & $100 \%$ \\
\hline G8 & 25 & $100 \%$ \\
\hline G9 & 45 & $100 \%$ \\
\hline
\end{tabular}

Source: Online Questionnaire

To understand the impact of the technological tool used to mediate the collaborative process, students were consulted about their previous experience with GD. From Table 8 it can be derived that there is no apparent relationship between the final products achieved (FP) and the previous experience that students have with the use of the GD tool. For example, none of the students of group G4, G6 and G9 had used it before, however the first two groups had a $95 \%$ rate of completion and the last $45 \%$.

Table 8. Results FP vs. previous experience with GD

\begin{tabular}{|c|c|c|}
\hline $\begin{array}{c}\text { Group } \\
\mathbf{N}^{\circ}\end{array}$ & FP & $\begin{array}{c}\text { Previous } \\
\text { experience with } \\
\text { GD }\end{array}$ \\
\hline G1 & 70 & $33 \%$ \\
\hline G2 & 75 & $75 \%$ \\
\hline G3 & 40 & $50 \%$ \\
\hline G4 & 95 & $0 \%$ \\
\hline G5 & 95 & $50 \%$ \\
\hline G6 & 95 & $0 \%$ \\
\hline G7 & 35 & $75 \%$ \\
\hline G8 & 25 & $40 \%$ \\
\hline G9 & 45 & $0 \%$ \\
\hline \multicolumn{2}{|c|}{ Source: Online questionnaire } \\
\hline
\end{tabular}

It is also important to note that $100 \%$ of students considered GD a useful tool to carry out the activity and mentioned that they would use it for other assignments or tasks.

\section{CONCLUSIONS}

The process of evaluating a collaborative activity can be very complex due to the variety of aspects to analyze. Additionally, the difficulty in identifying the individual contribution in a collaborative process causes some faculty to look skeptically at such processes. Hence it is important to design strategies and use tools to perform collaborative activities that allow identifying and fully evaluating the group and the individual performance.

When deciding to use a technological tool to facilitate collaborative work it is important to consider those technological tools that facilitate to the teachers the process of gathering information. In this sense would be easy for them to evaluate he group process and the individual contribution, and consequently they can be more motivated to integrate more often collaborative activities in their classrooms. Because GD is an easy and free tool that supports collaborative work, we considered relevant to assess and evaluate its potential within the collaborative process. As 
mentioned in [7] to analyze the process of collaboration is necessary to collect information on the process itself: about the participants, the individual actions, messages sent and received, as well as some ways to assess how participants carry out the collaborative process.

As presented in this article, GD provides information that allows assessing, in a relatively simple way, the group work based on the final product, and the individual contribution based on the number of contributions made by each member to this final product. However, this way to "measure" the individual contribution presents some drawbacks that could cause the facilitator not to evaluate individual work in a fair and equitable manner. Additionally, the tool does not provide facilities to assess the process of communication and organization of the group - a fundamental part of the collaborative work-so it is necessary to fill this gap with other information sources. The experience presented in this article, submits a final grade, considering the group work and individual contributions, from information provided by GD and a supplemental online questionnaire.

Now, if it is true that GD does not allow the recovery of messages sent by students, it is also true that semantic analysis of messages requires much time, becoming an impractical task for faculty. As part of future work we will work on identifying new tools and mechanisms that enable faculty to effectively assess the collaborative process in all its dimensions, with proper consideration for both, group contributions and individual contributions.

\section{ACKNOWLEDGMENTS}

This paper is developed as part of the project "RED u-CSCL: Red Iberoamericana de apoyo a los procesos de enseñanza-aprendizaje de competencias profesionales a través de entornos ubicuos y colaborativos, código CYTED 513RT0481".

\section{REFERENCES}

[1] J. Roschelle, R. Pea, C. Hoadley, D. Gordin, and B. Means, "Changing how and what children learn in school with computer-based technologies," Future Child, vol. 10, no. 2, pp. 76-101, 2000.

[2] D. Tatar, J. Roschelle, P. Vahey, and W. Penuel, Handhelds: Go to Scholl: Lessons Learned. IEEE Computer Society, 2003.

[3] M. E. Calzadilla, “Aprendizaje colaborativo y tecnologías de la información y la comunicación," Rev. Iberoam. Educ., vol. 1 , no. $10,2002$.

[4] M. Torgrude, "Why Handhelds in the Classroom," 2001.

[5] W. Y. Hsu, "Online education on campus: A technological frames perspective on the process of technology appropriation," Unpublished Doctoral Thesis, University of London, London, 2002.

[6] D. R. Garrison, T. Anderson, and W. Archer, "Critical Thinking and Computer Conferencing:A Model and Tool to Assess Cognitive Presence," Am. J. Distance Educ., vol. 1, 2001.

[7] C. Collazos, L. Guerrero, J. Pino, S. Renzi, J. Klobas, M. Ortega, M. Redondo, and C. Bravo, "Evaluating Collaborative Learning Processes using System-based Measurement," Educ. Technol. Soc., vol. 10, no. 3, pp. 257274, 2007.
[8] A. Ruda, "Percepción de los estudiantes sobre el uso de wiki. Análisis de una experiencia de aprendizaje colaborativo en la Universitat de Girona," Rev. Teoría Educ. Educ. Cult. En Soc. Inf., vol. 14, no. 1, pp. 76-100, 2013.

[9] A. Badia, "Aprender a colaborar con Internet en el aula," in Internet y competencias básicas, C. Monereo, Ed. Barcelona: Editorial Graó, 2005, pp. 93-116.

[10] M. Muhlenbrock, "A system for Analyzing Collaborative problem solving," 1999.

[11] D. Johnson and R. Johnson, Learning together and alone. Cooperation, competition and individualization. Englewood Cliffs, New Jersey.: Prentice Hall Inc., 1975.

[12] N. Scagnoli and M. Stephens, "Collaborative learning strategies in online education," presented at the Online Conference for Teaching and Learning (IOC2005), Illinois, 2005.

[13] F. Kirschner, F. Paas, and P. A. Kirschner, "Individual and group-based learning from complex cognitive tasks: Effects on retention and transfer efficiency," Comput. Hum. Behav., vol. 25, pp. 306-314, 2009.

[14] B. Rubia, I. Jorri, and R. Anguita, "Aprendizaje colaborativo y TIC," in Tecnología Educativa. La formación del profesorado en la era de Internet, J. D. P. Pons, Ed. Málaga: Aljibe, 2009.

[15] D. Johnson, R. Johnson, and E. Holubec, Advanced cooperative learning. Edina, MN: Interaction Books., 1992.

[16] E. F. Barkley, K. P. Cross, and C. H. Major, Collaborative learning techniques : a handbook for college faculty, 1st ed. San Francisco: Jossey-Bass, 2005.

[17] P. Dillenbourg, Collaborative learning: cognitive and computational approaches, 1st ed. Amsterdam; New York: Pergamon, 1999.

[18] C. Collazos and J. Mendoza, "Como aprovechar el aprendizaje colaborativo en el aula," Rev. Educ. Educ., vol. 9, no. 2, pp. 61-76, 2006.

[19] T. Koschman, A. Kelson, P. Feltovich, and H. Barrows, "Computer-supported problem-based learning: A principled approach to the use of computers in collaborative learning," CSCL Theory Pract. Emerg. Paradigm, pp. 83-124, 1996.

[20] G. Stahl, "Building collaborative knowing: Elements of a social theory of CSCL.," in What we know about CSCL: And implementing it in higher education, J.-W. Strijbos, P. A. Kirschner, and R. Martens, Eds. Boston, Mass.: Kluwer Academic Publishers, 2004, pp. 53-86.

[21] B. Gros and J. Silva, "La formación del profesorado como docente en los espacios virtuales de aprendizaje," Rev. Iberoam. Educ., vol. 36, 2005.

[22] L. Lipponen, "Exploring foundations for computersupported collaborative learning," in Proceedings of the Conference on Computer Support for Collaborative Learning: Foundations for a CSCL Community, 2002, pp. 72-81.

[23] R. López, La evaluación en la Universidad. Barcelona: Octaedro, 2002.

[24] L. Guerrero, R. Alarcón, C. Collazos, J. Pino, and D. Fuller, "Evaluating cooperation in group work," in Proceedings. Sixth International Workshop on Groupware, 2000, pp. 2835.

[25] J. McNamara and C. Brown, "Assessment of collaborative learning in online discussions," presented at the ATN Assessment 08: Engaging Students in Assessment, University of South Auustralia, 2008.

[26] C. Collazos, M. Alvira, R. Martínez, J. Jiménez, R. Cobos, and J. Moreno, "Evaluando y Monitoreando Actividades 
Colaborativas en Dispositivos Móviles," Av. En Sist. E Informática, vol. 5, no. 1, 2009.

[27] V. Basilotta and G. Herrada, "Aprendizaje a través de proyectos colaborativos con TIC. Análisis de dos experiencias en el contexto educativo," Rev. Electrónica Tecnol. Educ., vol. 44, 2013.

[28] J. Brindley, C. Walti, and L. Blaschke, "Creating effective collaborative learning groups in an online environment," Int. Rev. Res. Open Distance Learn., vol. 10, no. 3, pp. 1-8, 2009.
[29] A. Castellanos and A. Martínez, "Trabajo en equipo con Google Drive en la universidad online," Innov. Educ., vol. 13 , no. 63, 2013.

[30] G. Cenich and G. Santos, "Aprendizaje colaborativo online: indagación de las estrategias de funcionamiento," Rev. Iberoam. Educ. Educ. En Tecnol., vol. 1, pp. 1-8, 2007. 